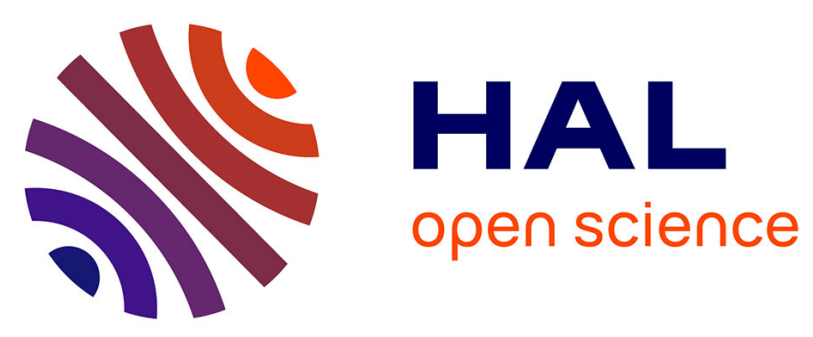

\title{
Experimental Evidence of Oxygen Thermo-Migration in PWR UO_2 Fuels during Power Ramps using In-situ Oxido-Reduction Indicators
}

\author{
C. Riglet Martial, J. Sercombe, J. Lamontagne, J. Noirot, I. Roure, T. Blay, \\ L. Desgranges
}

\section{To cite this version:}

C. Riglet Martial, J. Sercombe, J. Lamontagne, J. Noirot, I. Roure, et al.. Experimental Evidence of Oxygen Thermo-Migration in PWR UO_2 Fuels during Power Ramps using In-situ Oxido-Reduction Indicators. Journal of Nuclear Materials, 2016, 480, pp.32-39. 10.1016/j.jnucmat.2016.07.056 . cea02389290

\section{HAL Id: cea-02389290 https://hal-cea.archives-ouvertes.fr/cea-02389290}

Submitted on 2 Dec 2019

HAL is a multi-disciplinary open access archive for the deposit and dissemination of scientific research documents, whether they are published or not. The documents may come from teaching and research institutions in France or abroad, or from public or private research centers.
L'archive ouverte pluridisciplinaire HAL, est destinée au dépôt et à la diffusion de documents scientifiques de niveau recherche, publiés ou non, émanant des établissements d'enseignement et de recherche français ou étrangers, des laboratoires publics ou privés. 


\section{Experimental Evidence of Oxygen Thermo-Migration in PWR $\mathrm{UO}_{2}$ Fuels during Power Ramps using In-situ Oxido-Reduction Indicators}

Ch. Riglet-Martial, J. Sercombe, J. Lamontagne, J. Noirot, I. Roure, T. Blay, L. Desgranges

Commissariat à l'Energie Atomique et aux Energies Alternatives - Direction de l'Energie Nucléaire -

Département d'Etudes des Combustibles - Centre d'Etudes de Cadarache - 13108 Saint-Paul-lez-

Durance Cedex - France 


\section{Abstract}

The present study describes the in-situ electrochemical modifications which affect irradiated $\mathrm{PWR}^{\mathrm{U}} \mathrm{UO}_{2}$ fuels in the course of a power ramp, by means of in-situ oxido-reduction indicators such as chromium or neo-formed chemical phases. It is shown that sub-stoichiometric irradiated fuels under temperature gradient such as that occurring during high power transients are submitted to strong oxido-reduction perturbations, owing to radial migration of oxygen from the hot center to the cold periphery of the pellet. The oxygen redistribution, similar to that encountered in Sodium Fast Reactors fuels, induces a massive reduction/precipitation of the fission products $\mathrm{Mo}, \mathrm{Ru}, \mathrm{Tc}$ and $\mathrm{Cr}$ (if present) in the high temperature pellet section and the formation of highly oxidized neo-formed grey phases of $\mathrm{U}_{4} \mathrm{O}_{9}$ type in its cold section, of lower temperature. To our knowledge, it is the first time that such a phenomenon, likely to greatly impact the corrosive fission gas release, is experimentally attested for PWR fuels.

The parameters governing the oxidation states of $\mathrm{UO}_{2}$ fuels under power ramps are finally debated from a cross-analysis of our results and other published information. The potential chemical benefits brought by oxido-reductive additives in $\mathrm{UO}_{2}$ fuel such as chromium oxide, in connection with their oxygen buffering properties, are discussed.

Keywords: uranium, oxide, fuel, power ramp, power transient, temperature gradient, chromium, dopant, additive, solubility, thermodynamics, oxido-reduction, oxido-reductive, redox indicator, oxygen potential, thermo-migration, oxygen re-distribution.

*Corresponding author's e-mail: chantal.martial@ cea.fr 


\section{Introduction}

The composition and the thermochemical properties of nuclear fuel materials greatly affect their behavior under nominal or off-nominal operating conditions. Several important properties, such as thermal conductivity, solid-state diffusion, creep rate, or volatile fission gas (such as I, Te) speciation and release are directly correlated to temperature and oxygen partial pressure (or the $\mathrm{O} / \mathrm{M}$ ratio) in the fuel ${ }^{1,2}$. As those two parameters are likely to vary noticeably both in space and time during the fuel cycle, significant changes in the macroscopic material properties as well as in the speciation of the corrosive volatile gases, responsible for cladding ruptures are expected ${ }^{3,4}$.

Thus, the difficulty in establishing a coherent spatial and temporal map of the properties of an irradiated fuel stems essentially from the misunderstanding of the oxygen potential conditions taking place locally in the material, as a function of temperature, burn-up and irradiation history. Some direct oxygen potential measurements of irradiated fuels of UOX or MOX type in nominal operating conditions are described in the literature, for burn-ups varying between 30 and $100 \mathrm{GWd} / \mathrm{tM}$ and temperature values

varying between $700^{\circ} \mathrm{C}$ and $1000^{\circ} \mathrm{C}^{5,6,7,8}$. Most of the reported values, found in the vicinity of -400 $\mathrm{kJ} / \mathrm{mol} \mathrm{O}_{2}$, are consistent with a material which is oxygen buffered by the $\left(\mathrm{MoO}_{2} / \mathrm{Mo}\right)$ redox system resulting from the uranium fission, which is also in agreement with thermochemical predictions ${ }^{3,4}$. In the temperature range higher than $1000^{\circ} \mathrm{C}$, quantitative experimental data are very scarce. An estimation is given in a study of Kleykamp ${ }^{9}$, assuming that the two phase character of the molybdenum precipitates in the fuel sample (of $41 \mathrm{GWd} / \mathrm{tM}$ average burn up) is indicative of low oxygen potential values ranging between -376 and $-418 \mathrm{~kJ} / \mathrm{mol} \mathrm{O}_{2}$ at $1700{ }^{\circ} \mathrm{C}$. Another study from Adamson et al. ${ }^{10}$ refers to ex-reactor oxygen potential measurements using an emf oxygen probe, in oxide BWR fuels submitted to power ramps generating a temperature gradient ranging from around $500{ }^{\circ} \mathrm{C}$ at the fuel surface to above $1600^{\circ} \mathrm{C}$ at the fuel center. The measurements varying between -460 and $-560 \mathrm{~kJ} / \mathrm{mol} \mathrm{O}_{2}$ are indicative of some radial oxygen re-distribution phenomena inside the fuel under temperature gradient. In all published studies, the reported oxygen potentials data are based on either direct measurements using 
advanced emf oxygen probe or indirect estimates deduced from oxidation state observations of in-situ redox indicators such as fission products, impurities and the cladding.

In a previously published study from our laboratory ${ }^{11}$ dealing with the thermodynamics of chromium in $\mathrm{UO}_{2}$ fuel, we pointed out a direct correlation between chromium solubility in $\mathrm{UO}_{2}$ and oxygen partial pressure within the stability areas of $\mathrm{Cr}(\mathrm{sc})$ and $\mathrm{CrO}(1)$ phases in the $1500^{\circ} \mathrm{C}-2000{ }^{\circ} \mathrm{C}$ temperature range. This suggests that chromium might be advantageously used as an oxido-reduction indicator in irradiated $\mathrm{UO}_{2}$ fuel pellets submitted to high temperature, provided that the material including the fission products may be considered as a diluted solid solution, which is acceptable for fuels at low burnup $(<30 \mathrm{GWd} / \mathrm{tU})$.

The present study describes the in-situ-chemical modifications which affect chromium inside a $\mathrm{UO}_{2}$ fuel initially doped with $\mathrm{Cr}_{2} \mathrm{O}_{3}$ in the course of a power ramp of long holding time at high maximum power. Quantitative oxygen potential data in the $1500^{\circ} \mathrm{C}-2000{ }^{\circ} \mathrm{C}$ temperature range are deduced from the solubility measurements of chromium and the calculated temperature profile inside the pellet. The oxidation state of irradiated $\mathrm{UO}_{2}$ fuels submitted to a temperature gradient is finally discussed from a cross-analysis of our results and other published information. The potential chemical benefits brought by oxido-reductive additives in $\mathrm{UO}_{2}$ fuel are estimated.

\section{Notations}

$\begin{array}{lll}\text { PWR } & : & \text { Pressurized Water Reactor } \\ \text { BWR } & : & \text { Boiling Water Reactor } \\ \text { SEM } & : & \text { Scanning Electron Microscopy } \\ \text { EPMA } & : & \text { Electron Probe MicroAnalysis } \\ \text { SIMS } & : & \text { Secondary Ion Mass Spectroscopy } \\ \text { FP } & : & \text { Fission Products } \\ \text { emf } & : & \text { electro-motrice force }\end{array}$


(sc) : solid compound

(ss) : $\quad$ solid solution

(1) : liquid compound

\section{Experimental section - materials and methods}

Fuel rods of $\mathrm{UO}_{2}$ doped with $\mathrm{Cr}_{2} \mathrm{O}_{3}$ irradiated in commercial reactors were cut into sections and remanufactured into rodlets that experienced power ramps in OSIRIS experimental reactor ${ }^{12}$. Two power ramps named LHT, with a 12 hours holding time, at high power were performed. The main characteristics of the rods, the rodlets and the power ramps are given in Table 1.

The rodlets were transferred into hot cells after power ramp. Slices from the vicinity of the maximum power flux were cut and prepared in order to obtain sections which were further analyzed by means of various techniques : SIMS (described in [13]), EPMA and SEM. The sample preparation procedure is described in references [14] and [15]. On each sample, quantitative radial profiles of chromium and molybdenum were recorded by EPMA (see figures 1 and 3) from a line scan over the pellet radius with a step of 1 point / $10 \mu \mathrm{m}$. In addition, three distinct areas located in periphery, mid-radius and in the center of the pellet were observed in details by EPMA, X-ray map (EPMA) and electronic images (SEM).

\section{Experimental observations}

The radial profiles of chromium recorded on each power-ramped sample are shown in figures $1 \mathrm{a}$ and $1 \mathrm{~b}$. Likewise the figure 2 compares the $\mathrm{X}$-ray maps of chromium, oxygen, molybdenum and ruthenium in the pellet center for the sample LHT2. Superimposed in figures $1 \mathrm{a}$ and $1 \mathrm{~b}$ are the radial temperature profiles calculated with ALCYONE, a fuel performance code validated on a very large database of base irradiation, power ramps and annealing tests ${ }^{16}$.

Consistent observations are drawn from these two power-ramp tests. In the low temperature range of the pellet (cold section), between the periphery and the radial position that reached approximately $1400^{\circ} \mathrm{C}$, 
the soluble fraction of chromium in the $\mathrm{UO}_{2}$ matrix is measured around a constant value of 0.1 wt\% $\mathrm{Cr} / \mathrm{UO}_{2}$, regardless of temperature. The chromium fraction in excess is precipitated in $\mathrm{UO}_{2}$ as an oxide secondary phase. The chromium speciation (both soluble and insoluble forms) in the cold section of the rodlets is similar to that recorded on a pre-irradiated 5 cycles (burn-up $\sim 62 \mathrm{GWd} / \mathrm{tM}$ ) rod of the same type under nominal operating conditions (temperature varying between $500^{\circ} \mathrm{C}$ and $1000^{\circ} \mathrm{C}$ ). In the high temperature range of the pellet (hot section), between the radial position that reached $1500^{\circ} \mathrm{C}$ and the center of the pellet, the soluble fraction of chromium in $\mathrm{UO}_{2}$ decreases significantly down to the range $[0.05 \mathrm{wt} \%-0.09 \mathrm{wt} \%]$ and an abundant precipitation of metallic chromium is observed as a secondary phase. As shown on the X-ray maps in figure 2, chromium precipitates are both linked to a lack of oxygen and associated to some metallic FP solid phases including Mo and Ru. This co-localization is clearly highlighted when the EPMA profiles of molybdenum and chromium are superimposed as shown in figure 3. In the narrow transition area located at about mid-radius of the pellet $\left(\sim 1500^{\circ} \mathrm{C}\right)$, a drastic drop of the chromium solubility is observed and precipitates in secondary phase are present under two different redox states (oxidized and metal). Chromium oxide is detected as large precipitates whereas metallic chromium is identified as small precipitates.

\section{Interpretation}

\subsection{Low temperature range $\left(<1460^{\circ} \mathrm{C}\right)$ : Cold section of the pellet}

The chromium content in solid solution for each ramped rodlet was measured in the vicinity of $0.1 \mathrm{wt} \%$ $\mathrm{Cr} / \mathrm{UO}_{2}$ regardless of temperature, in the whole range $\left[20^{\circ} \mathrm{C}-1400^{\circ} \mathrm{C}\right]$. The chromium soluble content was equivalent to that of the initial un-irradiated fuel after sintering, measured to $0.102 \pm 0.004 \%{ }^{11,17,18}$. In addition, as compared to the initial un-irradiated fuel, the chemical form of the chromium precipitates of type $\mathrm{Cr}_{2} \mathrm{O}_{3(\mathrm{sc})}$ did not change during nominal condition irradiation, not even during ramp tests, regardless the burn-up and the characteristics of the ramp (power, duration...). It may then be stated that neither the temperature, nor the burn up, nor either the mode of irradiation affects the chromium 
speciation in the temperature range $\left[20^{\circ} \mathrm{C}-1460^{\circ} \mathrm{C}\right]$. Nevertheless, we verified in a previous study ${ }^{11}$ that both the stability of the $\mathrm{Cr}-\mathrm{O}$ solid/liquid phases and the solubility of chromium in $\mathrm{UO}_{2}$ were strongly dependent on temperature beyond $1500^{\circ} \mathrm{C}$. The fact that the solubility of chromium is unrelated to temperature at $\mathrm{T}<1450^{\circ} \mathrm{C}$ indicates that the spontaneous thermodynamic transformations of chromium in the $\mathrm{UO}_{2}$ matrix occurring at $\mathrm{T}>1500^{\circ} \mathrm{C}$ are strongly slowed, even inhibited a low temperature owing to the fact that the thermal energy brought to the system is not sufficient to exceed the energy barrier of the chemical transitions (highest energetic barrier for solid-solid type transformations). For that reason, in the low temperature range of a power ramp $\left(<1450^{\circ} \mathrm{C}\right)$ or in nominal operating conditions, chromium in the $\mathrm{UO}_{2}$ fuel stays in its initial stage reached after sintering. These assumptions were confirmed in our laboratory by further tests of long-time thermal annealing of $\mathrm{UO}_{2}$ pellets (initially doped with $1600 \mathrm{ppm} \mathrm{Cr}_{2} \mathrm{O}_{3}$ ) at the temperature of $1400^{\circ} \mathrm{C}$ and $1600^{\circ} \mathrm{C}$, all tests being carried out under reducing conditions $\left(\mathrm{Ar} / 5 \% \mathrm{H}_{2}\right)$ consistent with the thermodynamical stability of metal chromium. The analyses by SAX of the annealed samples showed that, at $1400^{\circ} \mathrm{C}$, the microstructure of the pellet did not change (absence of precipitate, chemical environment of solubilized chromium) as compared to its initial stage whereas a massive metal chromium precipitation was observed at $1600^{\circ} \mathrm{C}$, as thermodynamically expected. To conclude, at temperature lower than $1450^{\circ} \mathrm{C}$, chromium in $\mathrm{UO}_{2}$ does not change as compared to its initial stage reached after sintering, irrespective of both the oxygen potential conditions prevailing in that section of the pellet and the power cycle. Chromium is thus present in $\mathrm{UO}_{2}$ in disequilibrium with respect to oxido-reduction. Neither the stoichiometry of the solid precipitates (if present), nor the solubility of chromium in the matrix are consistent with the actual thermochemical conditions of the material.

\subsection{High temperature range $\left(>1460^{\circ} \mathrm{C}\right)$ : Hot section of the pellet}

\subsubsection{Thermodynamic equilibrium state}

Beyond the temperature of $1460^{\circ} \mathrm{C}$, an abrupt decrease of chromium dissolved in $\mathrm{UO}_{2}$ was evidenced by EPMA. This variation was coupled with a massive metal chromium precipitation in secondary phase. 
We think that this evolution is an indication of a switch from a kinetically controlled chemical system to a thermodynamically controlled one, the thermal energy brought to the system beyond $1450^{\circ} \mathrm{C}$ exceeding the energy barrier of the chemical transitions. This is accredited by the following observations. For temperatures ranging between about $1500^{\circ} \mathrm{C}$ and $2000^{\circ} \mathrm{C}$, the EPMA measurements collected in the ramped $\mathrm{UO}_{2}$ fuel vary continuously (Figure 4) in the interval $[0.04 \mathrm{wt} \% ; 0.09 \mathrm{wt} \%]$ in consistency with solubility measurements previously collected on laboratory samples submitted to similar experimental conditions ${ }^{11}$. That solubility variation was interpreted with a simple thermodynamic model with temperature and oxygen potential as main parameters ${ }^{11}$. Additionally, by plotting the variation of the chromium solubility in the LHT1 and LHT2 fuel samples as a function of temperature (Figure 4), an excellent reproducibility is obtained in the $\left[1800^{\circ} \mathrm{C}-2000^{\circ} \mathrm{C}\right]$ range in spite of different radial temperature gradients across the pellet. All these observations agree with the assumption of a chemical system evolving under thermodynamic control at high temperature.

\subsubsection{Chromium as a oxido-reduction tracer}

In ${ }^{11}$, a direct correlation was established between the chromium solubility in $\mathrm{UO}_{2}$ and the oxygen partial pressure within the stability areas of $\mathrm{Cr}_{(\mathrm{sc})}$ and $\mathrm{CrO}_{(\mathrm{l})}$ phases in the $1500^{\circ} \mathrm{C}-2000^{\circ} \mathrm{C}$ temperature range. As a consequence, the solubility of chromium might be advantageously used as an in-situ oxidoreduction tracer in $\mathrm{UO}_{2}$ fuel pellets submitted to high temperatures (off-nominal operating conditions). The oxygen potential variations in the power ramped $\mathrm{UO}_{2}$ rodlets of the LHT1 and LHT2 tests may be determined therefore from the solubility measurements of chromium in the $\left[1500^{\circ} \mathrm{C}-2000^{\circ} \mathrm{C}\right]$ range, using the solubility laws established earlier and the calculated temperature profiles over the pellet (coming from simulations with the fuel performance code ALCYONE). This interpretation is based on the assumptions that: i) thermodynamic equilibrium in the hot section of the pellet is reached (as discussed in section 5.2.1.), ii) the chromium solubility laws previously established on un-irradiated fuels are applicable i.e. the effect of fission products on chromium solubility is negligible at low burn-up (less than $30 \mathrm{GWd} / \mathrm{tU}$ ). 
A full interpretation of the experimental data on the power-ramped samples is given in figure 5, depicting the oxygen potential variation of the rodlets at equilibrium as a function of temperature in the $\left[1500^{\circ} \mathrm{C}-2000^{\circ} \mathrm{C}\right]$ range. The data were interpreted as developed in section 5.2.2 using the chromium solubility laws given in ${ }^{11}$ and recalled in table 1 . The interval $\left[1500^{\circ} \mathrm{C}-2000^{\circ} \mathrm{C}\right]$ corresponds to the validity range of the solubility model.

The calculated oxygen potential values are representative of the final thermochemical state of the $\mathrm{Cr}_{2} \mathrm{O}_{3}$ doped $\mathrm{UO}_{2}$ rodlets, after 12 hours of holding time at high power $\left(450-520 \mathrm{~W} . \mathrm{cm}^{-1}\right)$ without cladding failure. From the chromium iso-solubility curves shown in figure 5 , it appears that in the range $\left[1500^{\circ} \mathrm{C}\right.$ - $2000^{\circ} \mathrm{C}$ ], the region in accordance with solubility values ranging between around $0.04 \mathrm{wt} \%$ and $0.08 \mathrm{wt} \%$ corresponds to the metallic chromium $\mathrm{Cr}_{(\mathrm{s})}$ stability one. The solubility being the lowest in that area as compared to the $\mathrm{Cr}_{2} \mathrm{O}_{3(\mathrm{~s})}$ or $\mathrm{CrO}_{(\mathrm{l})}$ areas, a high precipitation of $\mathrm{Cr}_{(\mathrm{s})}$ is predicted, which is in agreement with the experimental observations.

\section{Discussion}

\subsection{Evidence of a reductive perturbation at high temperature during a power}

\section{transient}

The correlation depicted in figure 5 shows that the oxygen potential of the ramped rodlets of the LHT1 and LHT2 tests of initial burn-up close to $30 \mathrm{GWd} / \mathrm{tM}$ varies continuously between -450 and -380 $\mathrm{kJ} / \mathrm{mol} \mathrm{O}_{2}$ in the interval $\left[1500^{\circ} \mathrm{C}-2000^{\circ} \mathrm{C}\right]$. However, the oxygen potential of the initial Cr-doped pellets is to be expected in the vicinity of the limit between the $\mathrm{Cr}_{2} \mathrm{O}_{3}(\mathrm{sc})$ and $\mathrm{CrO}(\mathrm{l})$ stability domains ${ }^{11}$ (Figure 6) after sintering, which is a bit more oxidative. In addition, it is now acknowledged, from both experimental observations and thermochemical simulations, that the oxygen potential of irradiated $\mathrm{UO}_{2}$ fuels of burn-ups ranging from 30 to $60 \mathrm{GWd} / \mathrm{t} \mathrm{U}$ is even more oxidative as it is estimated in the vicinity of the $\left(\mathrm{MoO}_{2(\mathrm{~s}} / \mathrm{Mo}_{(\mathrm{s})}\right)$ redox couple. Therefore, as shown in figure 6 , the oxygen potential of the rodlets after completion of the power transient decreases drastically. Such a step in oxygen potential is 
significant enough to initiate the reduction into metal of the initial chromium oxide, as observed experimentally. In addition, the oxygen potential range reached after completion of the power ramp is also consistent with the stability of metallic molybdenum and ruthenium (figure 6). Thus, under high power-ramp conditions, the metallic chemical species $\mathrm{Mo}, \mathrm{Ru}$ and $\mathrm{Cr}$ are expected to precipitate in the hot section of the pellet, which agrees with the current observations. Thus, in consistency with thermochemical predictions, the observations confirm the existence of a strong reductive perturbation occurring in the hot section of the pellets during a power transient.

\subsection{Evidence of an oxidative perturbation at low temperature during a power}

\section{transient}

One can figure out the behavior of the fuel in the cold setion of the pellet from the recent paper of Desgranges et al. ${ }^{15}$ supporting the formation of a new highly oxidized solid phase around the grain boundaries near the pellet chamfer of a standard $\mathrm{UO}_{2}$ fuel rod (named LHT0 in table 3) ramped in similar conditions as that of the LHT1 and LHT2 specimens. This new phase of composition $\mathrm{U}_{4} \mathrm{O}_{9}$ which forms at the periphery of the pellet of low temperature (around $400^{\circ} \mathrm{C}$ ) can only be stabilized in conditions significantly more oxidative than that imposed by the reference $\left(\mathrm{MoO}_{2} / \mathrm{Mo}\right)$ redox couple (table 3 and figure 6). Thus, the occurrence of an oxidized uranium phase at the pellet chamfer gives evidence of a strong oxidative perturbation occurring in the cold section of the pellet during a power transient. As the system is closed, this oxidative perturbation is clearly correlated to the reductive perturbation taking place at the same time in the (hot) central part of the pellets.

\subsection{Oxygen redistribution in irradiated oxide fuels}

Published experimental oxygen activity data measured with various independent techniques, for irradiated $\mathrm{UO}_{2}$ fuels submitted to temperature gradients, are summarized in table 3 , together with the data issued from the current study. It is clear from the results of all tests that the fuel oxygen potential is drastically reduced as compared to the reference initial values $\left(\mathrm{MoO}_{2} / \mathrm{Mo}\right.$ redox couple) in the central 
area of the pellet whereas the region at the edge of the pellet may display a significant oxidation. The plot given in Figure 7 gives thus quantitative evidence that irradiation under a temperature gradient, such as that occurring during high power transient, causes radial oxygen redistribution from the hot central region of the pellet to the cold peripheral one, in consistency with the predicted direction of oxygen transport in hypo-stoichiometric oxide fuels $(\mathrm{O} / \mathrm{M}<2)^{19}$. Hence, the present results confirm that $\mathrm{UO}_{2}$ fuels of initial stoichiometry close to 2.000 become hypo-stoichiometric when irradiated, as a result of the accumulation with increasing burn-up of fission products of oxidation state lower than +4 . As expected then, they behave in the hot section of the pellet as hypo-stoichiometric fuels, when submitted to high power transients.

\section{Parameters governing the amount of re-distributed oxygen}

The amount of oxygen that is available for migration depends on both the initial stoichiometry and the burn-up $\left(\mathrm{O}_{2}\right.$ freed by the fission of $\left.\mathrm{UO}_{2}\right)$ of the fuel, as well as the amount of additive in oxide form $\left(\mathrm{O}_{2}\right.$ freed by reduction of the oxide) in the material, as long as this additive is involved in a redox couple that is likely to activate throughout the central reductive perturbation (like $\mathrm{Cr}_{2} \mathrm{O}_{3}-$ Figure 6): thus, the higher the burn up and the amount of oxydo-reductive additive, the larger the amount of oxygen available for transport. It is acknowledged moreover that the oxygen migrating to the cold peripheral region of the pellet contributes to increase the cladding oxidation ${ }^{10,20}$, which may greatly help to protect the later from corrosion by I-SCC during a power transient. This effect probably result from the chemical competition between iodine and oxygen which would be displaced in favor of oxygen. From these observations, it is deduced that an excess of oxygen in the $\mathrm{UO}_{2}$ fuel, coming either from an initial hyper-stoichiometry of the fuel or the presence of an oxido-reductive compound (like chromium oxide), or both, might be efficient to prevent clad failure by I-SCC during a high power transient. An optimization of the amount of additive needed is to be performed however as a function of the burn-up of the fuel, the power transient conditions (which govern the oxygen and corrosive fission products migration to the clad) and the nature of the dopant. 
In addition, the amount of oxygen which effectively migrates from the center to the edge of the pellet depends on the radial temperature gradient over the pellet directed related to the linear power rate imposed to it. It seems clear indeed from Adamson's results on the LIT/B3 test that the most severe cladding oxidation, that is the highest amount of oxygen coming to the clad, is linked to the strongest temperature gradient ${ }^{10}$.

\section{$\mathrm{O}_{2}$ re-distribution and oxygen potential shift at high temperature}

The shift of oxygen potential induced by the $\mathrm{O}_{2}$ re-distribution is directly linked to the amount of oxygen available for migration, also called the oxygen buffering capacity of the fuel, which is the total amount of oxygen available for transport, including the oxygen possibly coming from the additive. This oxygen buffering capacity increases with both the burn-up of the tested fuel and the amount of oxydoreductive additive (such as $\mathrm{Cr}_{2} \mathrm{O}_{3}$ ). As shown in Figure 7, the larger the buffering capacity, the shorter the oxygen potential jump in the hot region of the pellet. As reduced potential shifts induce minor redox perturbations inside the fuel in operation, larger oxygen buffering capacities involve a relative control of the material as regards its properties depending on $\mathrm{pO}_{2}{ }^{21,22}$ (buffering effect) which can be advantageous to compensate the strong perturbations induced by power ramps for example. Thus, as reported in ${ }^{1}$, addition of chromium oxide to $\mathrm{UO}_{2}$ results in enlarging the oxygen potential (or O/M) domain of minimal gaseous fraction for chemically reactive gases (I, Cs, Te), in $\mathrm{UO}_{2}$ fuel submitted to a reductive perturbation. In this area, the major gaseous species is $\operatorname{CsI}(\mathrm{g})$ which has little volatility and is quite unreactive towards the $\mathrm{Zr}$ cladding ${ }^{14,23}$. On that point of view, chromium oxide added to $\mathrm{UO}_{2}$ fuel is likely to act on both the volatile fission gas release and the corrosion risk of the cladding.

More generally, in connection with its buffering properties, one benefit of adding an oxido-reductive dopant inside an oxide fuel consists in reducing the possible drawbacks (creep rate changes, gas release enhancement, corrosion risk...) induced by strong redox perturbations on the material. Moreover, adding an oxido-reductive dopant contributes to increase the oxygen buffering capacity of the fuel, which may be beneficial for the prevention of clad-failure by I-CSC (iodine-oxygen competition displaced in favor of oxygen). 


\section{Conclusion}

The property of in-situ redox indicator of chromium was used to estimate in the $1500^{\circ} \mathrm{C}-2000^{\circ} \mathrm{C}$ range, the oxygen potential radial profile of some chromium doped $\mathrm{UO}_{2}$ fuels submitted to a power ramp of long holding time, without failure. It is shown that the oxygen potential of the rod in the range $\left[1500^{\circ} \mathrm{C}\right.$; $2000^{\circ} \mathrm{C}$ ] decreases down to $[-394 ;-410] \mathrm{kJ} / \mathrm{mol} \mathrm{O}_{2}$ during the power ramp, which is in the vicinity of the $\left(\mathrm{Cs}_{2} \mathrm{MoO}_{4(\mathrm{l})}, \mathrm{Cs}(\mathrm{l})+\mathrm{Mo}(\mathrm{s})\right)$ buffer system. These results imply that irradiated fuels submitted to temperature gradient such as power ramps are submitted to strong oxido-reduction perturbations, owing to radial migration of oxygen from the center to the periphery of the pellet. This phenomenon of oxygen redistribution, similar to that encountered in Sodium Fast Reactors fuels induces a massive reduction/precipitation of the fission products $\mathrm{Mo}, \mathrm{Ru}, \mathrm{Tc}$ and $\mathrm{Cr}$ (if present) in the high temperature pellet center and the formation of oxidized grey phases of cesium uranates or $\mathrm{U}_{4} \mathrm{O}_{9}$ type in its cold part, of lower temperature.

The amplitude of the oxygen potential jump during a power ramp is expected to depend on the temperature gradient (resulting from the linear power rate) and on the amount of oxygen available for migration (in connection with the initial sur-stoichiometry of the fuel, the burn-up of the rod and the amount of dopant if present). Thus, the addition to the fuel of an oxido-reductive dopant, such as chromium, contributes to enlarge its oxygen buffering capacity. One consequence is a reduction of the oxygen potential jump during a power ramp, as compared to standard rods of similar burn-up, which could be beneficial to buffer all key properties of the irradiated fuel dependent on oxygen (creep rate, thermal conductivity, fission gas speciation...). Another consequence is a possible better prevention against clad-failure by I-CSC during a power ramp, by displacing the iodine-oxygen competition to the clad inner surface in favor of oxygen.

It is therefore of great importance in PWR fuel performance codes to model oxygen radial redistribution during power ramps, not only for its impact on fuel properties, but also for its effect on corrosive fission gas release. An extension of this work will consist in applying the present methodology to other fuel 
rods submitted to varying power ramp conditions in order to improve the model of oxygen redistribution implemented in the ALCYONE code ${ }^{3,4}$.

\section{Acknowledgments}

The authors wish to thank AREVA NP and EDF for their financial and technical support in this study. Special thanks are addressed to Gérald Jomard from CEA whose careful relecturing of the paper gives rise to some improvements.

\section{References}

M. Conte, J. P. Gatesoupe, M. Trotabas, J. C. Boivineau, G. Cosoli, «Study of the thermal behaviour of LMFBR fuel", International conference on fast breeder reactor performance; Monterey, CA, USA; 5 - 8 March 1979.

Bogdan Mihaila, Marius Stan, Juan Ramirez, Alek Zubelewicz, Petrica Cristea, Journal of Nuclear Materials, Volume 394, Issues 2-3, November 2009, Pages 182-189.

B. Baurens, Thèse de l'Université d'Aix-Marseille (Ecole doctorale 352 - Physique et Sciences de la Matière), France (17 octobre 2014).

B. Baurens, J. Sercombe, Ch. Riglet-Martial, L. Desgranges, L. Trotignon, P. Maugis, Journal of Nuclear Materials, Volume 452, Issues 1-3, September 2014, Pages 578-594.

$5 \quad$ Matzke Hj., Journal of Nuclear Materials, 208, 18-26 (1994).

$6 \quad$ Matzke Hj., Journal of Nuclear Materials, 223, 1-5 (1995).

$7 \quad$ K. Une, Y. Tominaga, S. Kashiba, Journal of Nuclear Science Technology, 28 (1991) 409. 
Walker C.T., Rondinella V.V., Papaioannou D., Van Winckel S., Goll W., Manzel R., Journal of Nuclear Materials, 345, 192-205 (2005).

Kleykamp H., Journal of Nuclear Materials, 84, 109-117 (1979).

M. G. Adamson, E. A. Aitken, S. K. Evans, J. H. Davies, Symposium on the thermodynamics of nuclear materials; Vienna, Austria ; 21 Oct 1974 ; IAEA-SM 190/54.

Ch. Riglet-Martial, Ph. Martin, D. Testemale, C. Sabathier-Devals, G. Carlot, P. Matheron, X. Iltis, U. Pasquet, C. Valot, C. Delafoy, R. Largenton, Journal of Nuclear Materials, Volume 447, Issues 1-3, April 2014, Pages 63-72. C. Mougel, B. Verhaeghe, C. Verdeau, S. Lansiart, S. Béguin, B. Julien, "Power ramping in the OSIRIS reactor : database analysis for standard $\mathrm{UO}_{2}$ fuel with $\mathrm{Zy}-4$ cladding", in Pellet Cladding Interaction in Water Reactor Fuels, OECD/NEA Nº6004 (2005) 333-345.

B. Rasser, L. Desgranges, B. Pasquet, Appl. Surf. Sci. 203-204(2003) 673-678.

L. Desgranges, Ch. Riglet-Martial, I. Aubrun, B. Pasquet, I Roure; J. Lamontagne, Th. Blay, Journal of Nuclear Materials, Volume 437, Juin 2013, Pages 409-414.

L. Desgranges, J. Lamontagne, Ch. Riglet-Martial, Th. Blay, Journal of Nuclear Materials, Volume 457, February 2015, Pages 246-251.

16

C. Struzik C., V. Marelle, "Validation of fuel performance CEA code ALCYONE, scheme 1D, on extensive database”, Top Fuel 2012, Manchester, United Kingdom, 2 - 6 September 2012.

T. Cardinaels, K. Govers, B. Vos, S. Van den Berghe, M. Verwerft, L. de Tollenaere, G. Maier, C. Delafoy, Journal of Nuclear Materials. 424 (2012) 252-260. 
A. Leenaers, L. de Tollenaere, Ch. Delafoy, S. Van den Berghe, Journal of Nuclear Materials. 317 (2003) 62-68.

19 C. Sari, G. Schumacher, Journal of Nuclear Materials, Volume 61, Issue 2, August 1976, Pages 192-202.

J.H. Davies, E.V Hoshi, D.L Zimmerman, Journal of Nuclear Materials, Volume 270, Issues 1-2, 1 April 1999, Pages 87-95.

P. T. Sawbridge, G. L. Reynolds, B. Burton, Journal of Nuclear Materials 97 (1981) 300-308. 216-220.

23

K. Konashi, T. Yato, H. Kaneko, Journal of Nuclear Materials, 116 (1983) 86. 